\title{
Ordu-Giresun Havalimanı'nın sürekli saçıcılar interferometrisi (PSI) ile deformasyon analizi
}

\author{
Çağlar Bayık ${ }^{1^{*} \mid \mathbb{P}}$ \\ 'Zonguldak Bülent Ecevit Üniversitesi, Mühendislik Fakültesi, Geomatik Mühendisliği Bölümü, Zonguldak, Türkiye.
}

Öz: Günümüzde pek çok ülke, hızl kentleşmenin getirmiş olduğu arazi taleplerini karşılayamamaktadır. Özellikle kıyı kentleri için bu sorun daha da büyüktür ve problemi ortadan kaldırmak amactyla dolgu projeleri üretilmektedir. Ülkemizde de bu tip projelere benzer pek çok uygulama yapılmaktadır. Bu projelerin en önemlilerinden birisi de Ordu-Giresun il sınırına yakın Doğu Karadeniz kıyılarına yapılmıs olan Ordu-Giresun Havalimanı'dır. Deniz üzerine dolgu ile inşa edilen arazinin temelleri yerleşime duyarl ve jeolojik olarak hareketli bir yapıya sahiptir. Bu durum özellikle nüfusu fazla olan alanlarda olumsuz etkilere sebep olabilmektedir. Bu tür alanlar üzerine inşa edilen havalimanlarında işletme güvenliğinin sağlanması kamu güvenliği açısından oldukça hayati bir öneme sahiptir ve bu güvenliğin sağlanmast için bölgesel ölçekte yüzey deformasyonu izlenmelidir. Bu çalışmada 2011 yılında temeli atılıp 2015 yılında faaliyete geçen Ordu-Giresun Havalimanı'nın yüzey deformasyonu belirlenmiştir. Bu amaçla Sentinel-1A/B görüntüleri, aynı alanları kapsayan geometride alçalan yörüngede elde edilerek Sürekli Saçıcılar Interferometrisi (PSI) tekniği ile zaman serileri analiz edilmiştir. Zaman serileri, PSI yaklaşımıyla ücretsiz olarak kullanıcıya sunulan SNAP ve Sürekli Saçıcılar için Stanford Yöntemi (StaMPS) paket programları kullanılarak oluşturulmuştur. Gerçekleştirilen analiz sonucunda Ağustos 2017 ve Şubat 2019 tarihleri arasında Ordu-Giresun Havalimanı'ndaki deformasyon miktarı yaklaşı -14 ila $9 \mathrm{~mm}$ arasında olduğu belirlenmiştir. İlerleyen dönemlerdeki çalışmalarda havalimanının daha geniş zaman aralı̆̆ında ve iki farklı yörüngede deformasyonunun izlenmesi planlanmaktadır.

Anahtar Sözcükler: Deformasyon, PSI, Ordu-Giresun Havalimanı, Sentinel-1, InSAR

\section{Deformation Analysis of Ordu-Giresun Airport by Persistent Scatterer Interferometry (PSI)}

\begin{abstract}
Nowadays, many countries cannot meet the land demands caused by rapid urbanization. This problem is even greater especially for coastal cities and land filling projects have been produced in order to eliminate this problem. In Turkey, there are also many applications similar to this type of projects. One of the most important of these projects is Ordu-Giresun Airport, which was built on the Eastern Black Sea coast close to the Ordu-Giresun provincial border. The foundation of the land, which was built with filling on the sea, is sensitive to settlement and geologically active. This can have adverse effects especially in areas with high population. Ensuring operational security at airports built on such areas is vital in terms of public security and surface deformation should be monitored at regional scale to ensure this security. In this study, the surface deformation of Ordu-Giresun Airport, which was founded in 2011 and became operational in 2015, was determined. For this purpose, Sentinel-1A/B images were obtained in a descending trajectory in geometry covering the same areas, and time series were analyzed with the Persistent Scatterer Interferometry (PSI) technique. Time series were created by using SNAP and Stanford Method Permanent Distributions (StaMPS) package programs offered to the user free of charge with the PSI approach. As a result, it was determined that the deformation at Ordu-Giresun Airport between August 2017 and February 2019 was approximately rates from -14 to $9 \mathrm{~mm}$. In future studies, it is planned to monitor the deformation of the airport in a wider time interval and in two different orbits.
\end{abstract}

Keywords: Deformation, PSI, Ordu-Giresun Airport, Sentinel-1, InSAR 


\section{Giriş}

Günümüzde, giderek artan ekonomik kalkınma hızı göz önüne alındığında birçok sahil kenti, kentsel ve inşaat yatırımlarında olduğu kadar ulaşım için de yapı alanı sıkıntısı çekmektedir (Hoeksema, 2007). Artan bu ihtiyacı karşılamak için, dünya genelinde birçok kıyı ülkesinde denize yapılan dolgu alanlar ile toprağın geri kazanılması yaygın bir uygulama haline gelmiştir. Geçtiğimiz on yıllarda, bu geri kazanım yöntemi çeşitli arazi kullanım taleplerine yanıt vermiştir ve özellikle hava taşımacılığına oldukça fayda sağlamıştır. Kıyısı bulunan şehirlere hizmet veren birçok yeni havalimanı, nüfusun daha az olduğu bölgelerde ve denize daha yakın alanlarda inşa edilmiştir (Douglas \& Lawson, 2003).

Dünyadaki yönelime paralel olarak ülkemizde de birçok yapı ve inşaat faaliyeti deniz üzerine dolgu yöntemiyle yapıllmıştır. $\mathrm{Bu}$ yöntem ile inşa edilen tek havalimanı olan Ordu-Giresun Havalimanı yapılacak olan diğer projeler için bir öncü olmuştur. Şu anda Ordu-Giresun Havalimanı dışında Rize ve Artvin illeri arasında, 2017 yılında temeli atılan ve inşaatı devam eden Rize-Artvin Havalimanı projesi bulunmaktadır.

Deniz üstü dolgu ve yapı inşaatı için kullanılan bir alan, toprak parçası olarak kısa bir geçmişe sahip olduğundan, zayıf bir temel jeolojisine ve çok düşük stabilizeye sahiptir. Bu sebeple, bu tür alanlar üzerine inşa edilen havalimanları için temel yerleşimi önemli bir problemdir. Özellikle toprak üzerinde bulunan binalarda ve altyapıda meydana gelebilecek çatlamalar veya çökmeler önemli bir sorun teşkil etmektedir. Tehdit edici ve yüksek risk taşıyan bu yapılardaki mevcut veya potansiyel deformasyonun belirlenmesi ve izlenmesi risklerin değerlendirilmesinde hayati önem taşımaktadır. Özellikle havalimanı pistlerindeki hasarın önlenmesi amacıyla uygun önlemlerinin alınabilmesi için bu değişim mekanizmalarını anlamak çok önemlidir.

Geçtiğimiz birkaç on yılda, interferometrik sentetik açıklıklı radar (Interferometric Synthetic Aperture Radar, InSAR) yöntemi etkili bir jeodezik araştırma tekniği olarak geliştirilmiştir. InSAR ile gerçekleştirilen deformasyon ölçmeleri, Global Navigasyon Uydu Sistemleri (GNSS) ve nivelman gibi geleneksel yöntemlere göre yüksek hassasiyet, düşük maliyet ve büyük ölçekte bir gözlem olanağ1 sağlamaktadır (Chen vd., 2015). InSAR tekniği; sismik deformasyon (Hu vd., 2012), depremler (Simons, Fialko, \& Rivera, 2002), yeraltı su çıkarımı (Chen vd., 2016), volkan dinamikleri (Pritchard \& Simons, 2004), heyelanlar (Ye, Kaufmann, \& Guo, 2004) gibi jeolojik süreçler dahil olmak üzere pek çok jeofizik olayını araştırmak için kullanılmıştır. Ayrıca 2007 yılı Yapay Açıklıklı Radar (SAR) görüntüleme teknolojisi için bir devrim yılı olmuştur. Yeni nesil uydular olan Cosmo-SkyMed ve TerraSAR-X ile 1m mekansal çözünürlüğe ulaşılmış ve bu uydu verileri ile üretilen Sayısal Yüzey Modellerinin (SYM) daha önceki uydu misyonlarına göre kaliteyi arttırdığı bir dönem başlamıştır (Capaldo, Crespi, Fratarcangeli, Nascetti, \& Pieralice, 2011; Sefercik, Yastıklı, \& Atalay, 2017). InSAR tekniği aynı zamanda madencilik (Abdikan, Arıkan, Şanlı, \& Çakır, 2014), delta batması (Higgins vd., 2014) ve arazi çökmesi (Garthwaite, 2017) gibi insan faaliyetlerinin neden olduğu zemin deformasyonunun izlenmesinde de kullanılabilir.

Geleneksel InSAR tekniği farklı uydu pozisyonları, uzun veri edinim aralığı ve atmosferik değişimlerin neden olduğu zamansal-konumsal ilişki ve atmosferik gecikme gibi bazı sınırlamalar içermektedir (Hanssen, 2001). Bu sınırlamalar nedeniyle Diferansiyel InSAR (DInSAR) tarafından sağlanan deformasyon izleme doğruluğu ancak desimetreden santimetreye kadar belirlenebilir. Ayrıca kentsel alan ve yapı alanlarını izleme uygulamalarında hâlihazırda büyük sınırlamalar mevcuttur. Tekniğin uygulanmasındaki bu kısıtlamalar InSAR uygulamalarının genişletilerek deformasyonların zaman serisi biçiminde izlenmesini uygun hale getirmiştir. Sürekli saçıcılar interforometrisi (Persistent Scatterer Interferometry, PSI), geleneksel InSAR tekniği üzerindeki tutarsızlık sınırlamasının üstesinden gelmek için geliştirilmiştir (Ferretti, Prati, \& Rocca, 2001). PSI, milimetre düzeyinde bir deformasyon hızı haritası oluşturmak için Sürekli Saçıcılar 
(Persistent Scatterer, PS) ile her deformasyonun zamansal davranışını izlemek için geliştirilmiştir.

Son yıllarda, en yüksek işletme güvenliği ve emniyet standartlarını sağlamak için uluslararası havalimanlarının bölgesel ölçekte deformasyonunu izlemek bir öncelik haline gelmiştir. Bu bağlamda, ulaşım altyapılarını izlemek amacıyla en yenilikçi ve uygun teknikler arasında yer alan PSI teknolojisinin zemin deformasyonlarını araştırmak için etkili bir teknik olduğu kanıtlanmıştır (Bianchini Ciampoli vd., 2020; Gao vd., 2019; Jiang, Liao, Wang, Zhang, \& Balz, 2016; Marshall vd., 2018).

Bu çalışmada, PSI tekniğini kullanarak Ordu-Giresun Havalimanı alanındaki lokal yer değiştirmelerin zamansal olarak belirlenmesi, tanımlanması ve anlaşılması amaçlanmaktadır. Bu amaçla Ağustos 2017'den Şubat 2019'a kadar elde edilen 84 adet alçalan yörüngeye ait Sentinel-1A ve Sentinel-1B uydu görüntü veri kümesi kullanılarak lokal yer değiştirmeler ve bunların zamansal eğilimi milimetre ölçeğinde belirlenmiştir.

\section{2. Çalışma Alanı}

Çalışma Türkiye'nin Doğu Karadeniz Bölgesi kıyısında bulunan Ordu-Giresun Havalimanı alanında gerçekleştirilmiştir. Havalimanı deniz üzerine dolgu ile inşa edilmiş bir kamu havalimanıdır ve Türkiye'nin deniz üzerine dolgu ile inşa edilen ilk havalimanı olma özelliğine sahiptir. Adından da anlaşılacağı üzere havalimanı sahası Ordu ve Giresun il sınırının bulunduğu bölgede bulunup Ordu il sınırları içinde yer almaktadır (Şekil 1).
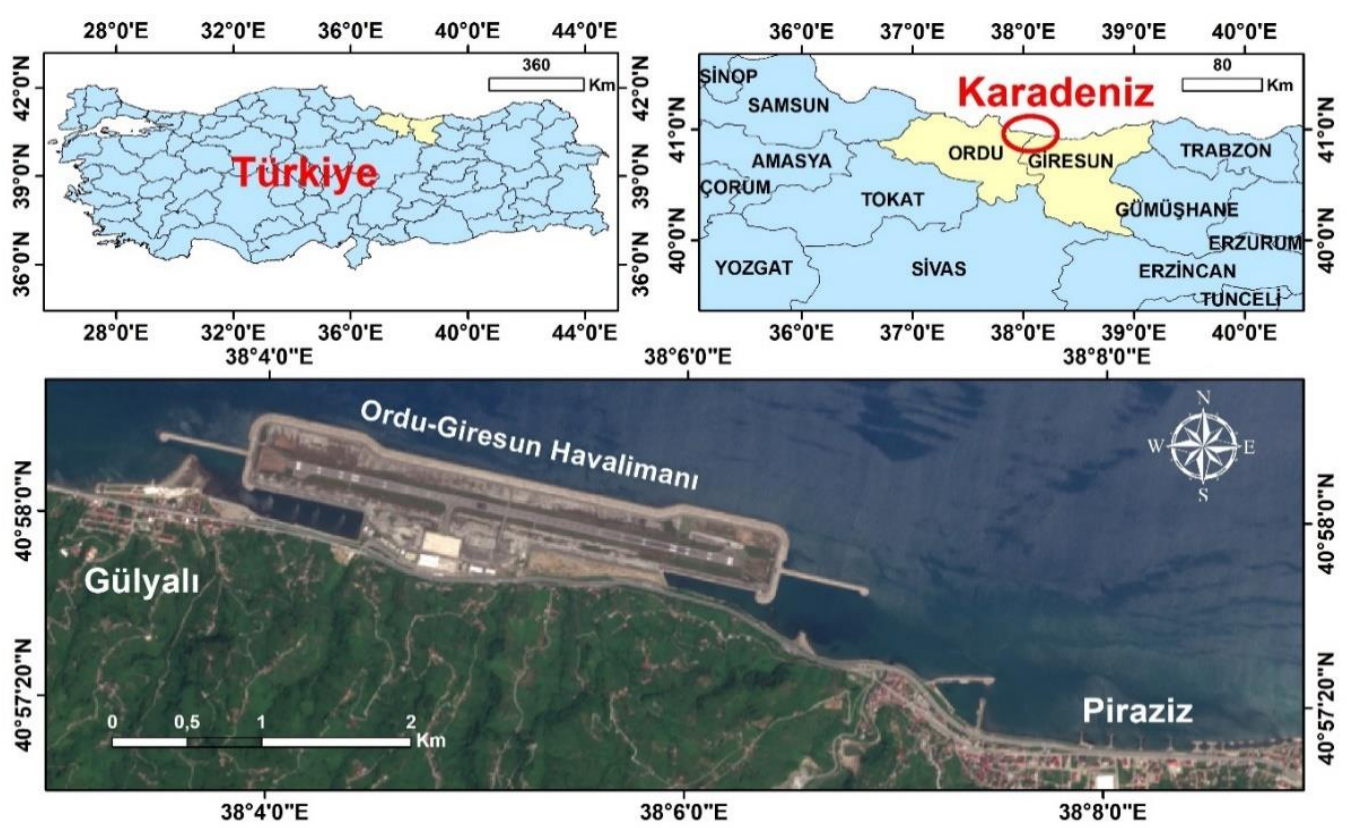

Şekil 1: Çalışma alanı

Bölge topoğrafyasının oldukça eğimli ve engebeli olması nüfus yoğunluğunun düşük kalmasına sebep olmuştur (Şekil 2). Aynı sebepten dolayı ulaşım gelişemediği için ekonomi ve turizm yönünden de zayıf kalmıştır. Bölgenin gelişimi için hava ulaşımı alternatifi düşünülmüş fakat düz ve eğimi az olan bölgelerde yerleşimler bulunduğu için havalimanı inşaatına uygun bir alan bulunamamıştır. Sonunda denize dolgu ile inşa edilmeye karar verilen havalimanı için 2011 yılında temel atılmış, 2015 yılında hizmete açılmıştır (Türk, 2015). Havalimanı yapımında üst ve altyapıları korumak için yaklaşık 7.5 km uzunluğunda ve ortalama 5.5 m yüksekliğinde taşlarla dolgu yapılarak mendirek inşa edilmiştir. Havalimanı pisti 3 km uzunluğunda ve 45 m genişliğindedir (URL-1). 


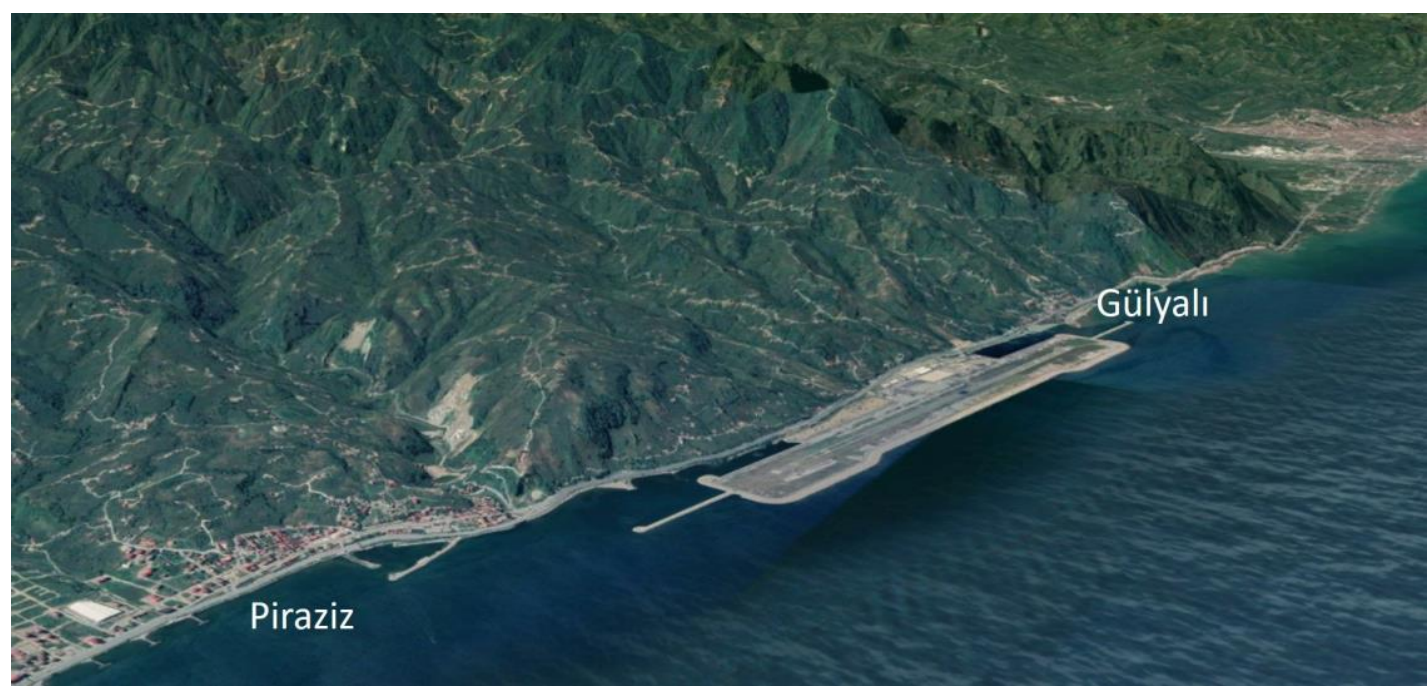

Şekil 2: Çalışma alanı ve topoğrafyasının Google Earth görünümü

\section{InSAR Gözlemleriyle Yüzey Hareketlerini Belirleme}

PSI aynı yörüngede bulunan birden fazla SAR görüntüsünü işleyerek sinyallerdeki bozulmayı azaltmayı amaçlamaktadır. Bu yöntem sayesinde en iyi sinyal, zaman serisi analizi olarak da bilinen PSI ile elde edilmektedir (Ferretti, Prati, \& Rocca, 2001). PS merkezinden alınan dominant yansıma prensibine dayanan PSI yöntemi, ilgisiz nokta hedeflerinin tamamen ortadan kaldırılmasına neden olur. PSI, görüntüleri piksellerin faz değerlerini kullanarak bir zaman serisinde kullanır (Ferretti, Prati, \& Rocca, 2000; Hooper, Zebker, Segall, \& Kampes, 2004; Kampes, 2006).

Çalışmada kullanılan Sentinel-1 A/B verileri ücretsiz olarak Avrupa Uzay Ajansı'ndan (European Space Agency, ESA) temin edilmiştir. Tüm görüntüler tek bakışılı karmaşık (Single Look Complex, SLC) görüntü formatında VV polarizasyonunda elde edilmiştir. Yüzey deformasyonunu belirlemek için, Sentinel-1 interferometrik geniş şerit mod (Interferometric Wide Swath, IW) görüntüleri Ağustos 2017-Şubat 2019 dönemini kapsayacak şekilde işlenmiştir. Sentinel-1 görüntülerinin her biri üç IW şeritten (sub-swath) oluşur. Her bir şerit ayrıca dokuz parçaya (burst) bölünür ve her parça ayrı bir SLC görüntüsü olarak işlenebilir. Sentinel-1A ve Sentinel-1B, beraber 6 gün gibi kısa bir zamansal baz uzunluğu sağlar. Bu özellik, zaman serisi çalışmaları için büyük bir avantajdır. InSAR tekniği ile yüzey yer değiştirmelerini belirlemenin avantajlarından biri de, alçalan ve yükselen yörüngelerde görüntü elde edilebilmesidir. Analizler için toplamda 84 alçalan yörünge görüntüsünden oluşan bir veri kümesi kullanılmıştır. Görüntü özelliklerinin ayrıntıları Tablo 1'de gösterilmektedir. Veri seçimi sırasında, çerçeveler mümkün olduğunca çok sayıda görüntü için aynı yörüngeden seçilmiştir. Bu nedenle, veri setinde mevsimsel ayrım gözetilmemiştir. PSI yönteminde master belirlemek için meteorolojik veriler de kullanılmıştır.

Tablo 1: Kullanılan SAR görüntülerinin özellikleri

\begin{tabular}{cc}
\hline Algllayıcı & Sentinel-1 \\
\hline Yörünge & 21 \\
\hline Geçiş yörüngesi & Alçalan \\
\hline Modu & IW \\
\hline Dalga boyu & C-bant: $\sim 5.6 \mathrm{~cm}$ \\
\hline Geliş açısı & $\sim 39^{\circ}$ \\
\hline Polarizasyon & VV \\
\hline Periyot & $20170804-20190207$ \\
\hline Görüntü sayısı & 84 adet \\
\hline
\end{tabular}


Analizlere ait işlem adımları Şekil 3’te sunulmaktadır. Öncelikle Sentinel-1 görüntülerinin ön işlenmesi, açık kaynak Sentinel Uygulama Platformu (SNAP) yazılımı ile gerçekleştirilmiştir. Sonrasında ise PS seçimi, SYM hata düzeltmesi ve interferogramların çözümleme (unwrapping) işlemi açık kaynaklı StaMPS (Stanford Method for Persistent Scatterers) yazılımı ile yapılmıştır (Hooper vd., 2010). Şekil 4'te gösterildiği üzere görüntü eşleştirme işleminde, interferogramlar tek bir master görüntüye bağlı geometride üretilmiştir. InSAR verilerinden topografik faz etkisini kaldırmak için SYM olarak 30 m çözünürlüklü SRTM verisi kullanılmıştır. Çalışmada kullanılan koordinat sistemi WGS84’tür.

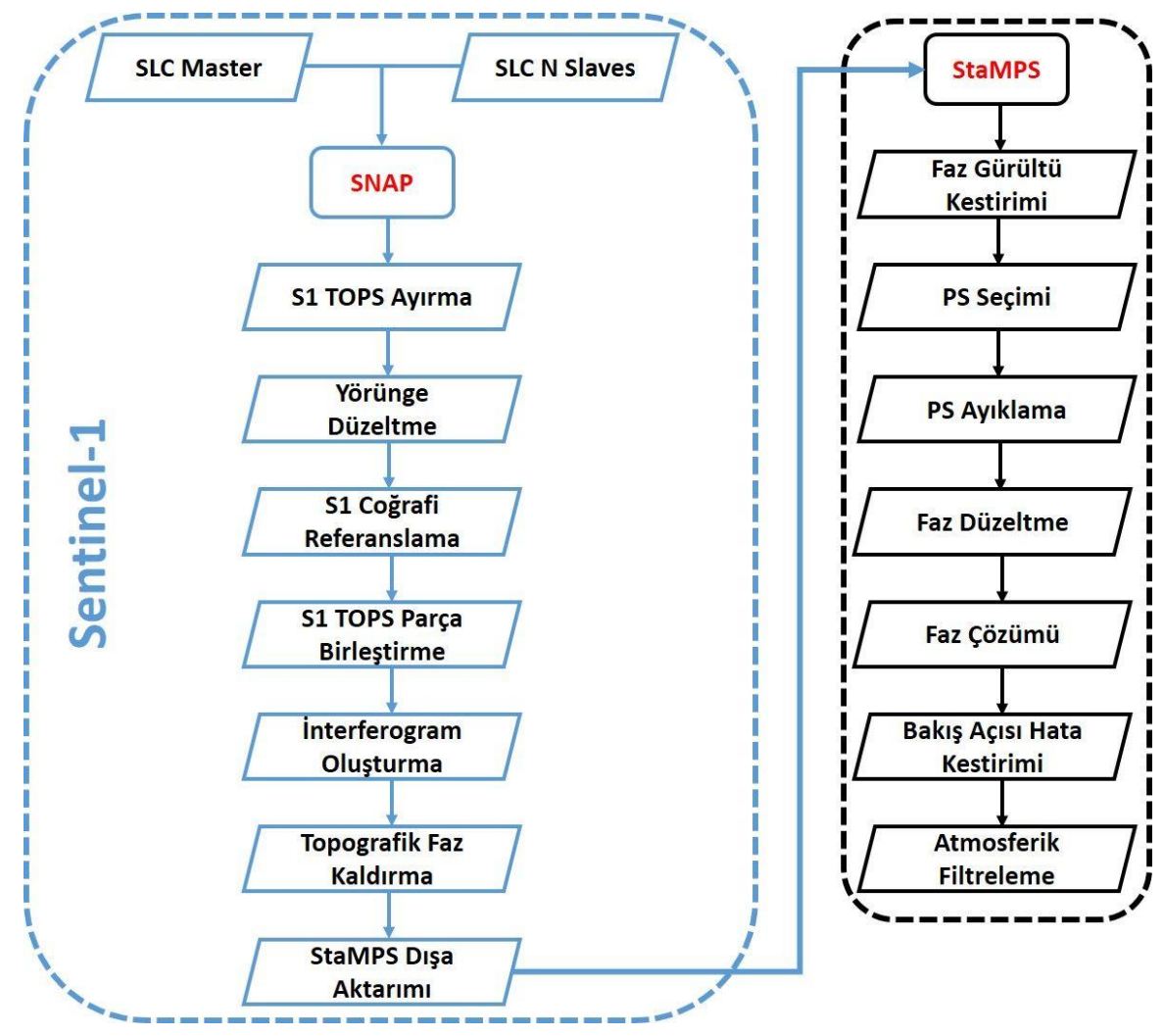

Şekil 3: SNAP ve StaMPS işlem adımları

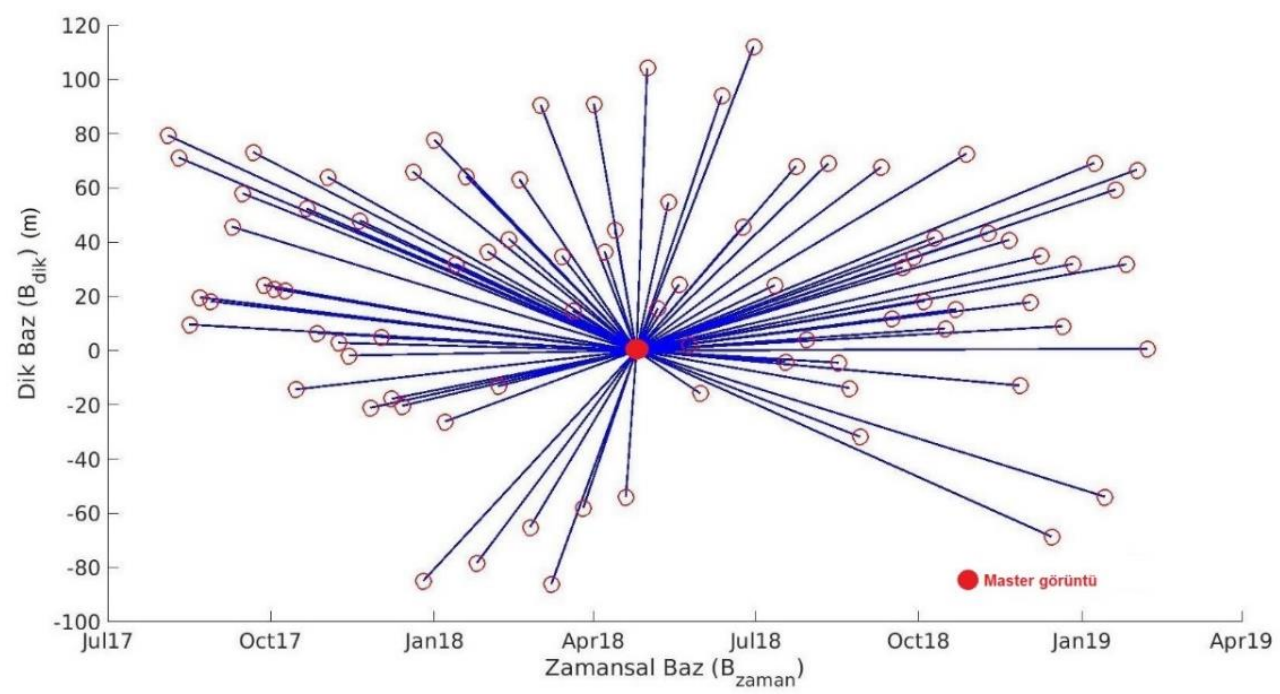

Şekil 4: Sentinel-1 zamansal ve geometrik bazlar 


\section{Bulgular ve Tartışma}

Havalimanlarının üzerine kurulduğu zeminin stabilizesi, işletme faaliyetlerinin düzenli olarak çalışması için çok önemlidir. Zeminde meydana gelen yüzey deformasyonlarının, özellikle uçakların iniş ve kalkışı sırasında pistlere ve terminallere risk oluşturma potansiyeli mevcuttur. Bu tip deformasyonlar özellikle denizden geri kazanılan arazi üzerine inşa edilen havalimanlarında meydana gelmektedir. Lap Kok Havalimanı (Hong Kong, Çin) (Liu, Ding, Chen, Li Zhilin, \& Li Zhiwei, 2001), Kansai Uluslararası Havalimanı (Osaka, Japonya) (Puzrin, Alonso, \& Pinyol, 2010), Pekin Başkent Uluslararası Havalimanı (Pekin, Çin) (Dai vd., 2020), San Francisco Uluslararası Havalimanı (San Francisco, ABD) (URL-2) gibi denizden geri kazanılan arazi üzerine inşa edilen düzinelerce havalimanında bu tip deformasyonlara rastlanmıştır. Bu havaalanlarından Hong Kong Uluslararası Havalimanı'nın yüzeyinde meydana gelen çökmeler PSI tekniğiyle ERS-1, ERS2 ve ENVISAT ASAR uyduları kullanılarak izlenmiş ve çökmeler belirlenmiştir (Ding, Liu, Li Z.W., Li Z.L., \& Chen, 2004; Zhao vd., 2011). Bir başka çalışmada Pudong Uluslararası Havalimanı'nda oluşan çökmeler belirlenmiş, çökme özellikleri ve çökmenin itici güçlerini incelemek için yüksek çözünürlüklü TerraSAR-X görüntüleri kullanılmıştır (Jiang vd., 2016). Çin'de ise 2016 yılında ıslah edilmiş bir alan üzerine inşa edilen Xiamen Xiang’an havalimanında meydana gelen çökme 1.5 yıllık Sentinel-1 verileri ile incelemiştir (Zhuo vd., 2020).

Araştırmalar, arazi ıslahı ile ilişkili arazi deformasyonunun temel nedenleri olarak birincil konsolidasyon, ıslahın altındaki alüvyonlu kil yataklarının uzun vadeli ikincil sıkıştırması ve ıslah dolgusunun kayması olmak üzere üç temel mekanizmayı işaret etmektedir (Jiang \& Lin, 2010; Plant, Covil, \& Hughes, 1998; Terzaghi, Peck, \& Mesri, 1996; Xu vd., 2016; Yang vd., 2018). Arazi ıslahından sonraki arazi deformasyonunun büyüklüğü ve hızı, öncelikli olarak ıslah edilen malzemelerin türü ve kalınlığı, alttaki alüvyonlu çökeltilerin kalınlığı, ıslahın tamamlanmasından sonraki süre ve temel işlemenin etkisine bağlıdır (Pickles \& Tosen, 1998). Toplam deformasyonun en büyük bölümü, alüvyonlu killerin birincil konsolidasyonundan kaynaklanmaktadır ve denizden geri kazanılan arazi üzerine inşa edilen havalimanlarında bu oran genellikle \%70'in üzerindedir (Jiang \& Lin, 2010). Ayrıca, birincil konsolidasyonun çökme süreci, ikincil sıkıştırma ve 1slah dolgusunun kaymasından çok daha hızlı meydana gelmektedir (Terzaghi, Peck, \& Mesri, 1996).

T.C. Ulaştırma, Denizcilik ve Haberleşme Bakanlığı (2012) raporuna göre, Ordu-Giresun Havalimanı’nın inşa edildiği dolgu arazisi genel olarak geçmiş çalışmalara konu olan havalimanlarına benzer yapıdadır. Dolgu arazisi kum ve alüvyonlardan oluşan iri çakıl tabakalarından oluşmaktadır. Oluşturulan bu dolgunun ilk tabakası gevşek olarak ifade edilen yapıya sahiptir. Dolgu sürecinde üstüne gelen ağırlıkla orta sıkı zemin özelliğine kavuşacağı öngörülmektedir. Kumlu çakıldan oluşan diğer tabaka ise ilk tabakaya göre daha sert bir yapıya sahiptir. En sert tabaka olan yüzey tabakası ise sıkı kum ve iri çakıllardan oluşmaktadır. Söz konusu yapısı nedeniyle deprem ve ekstrem hava şartlarının sebep olabileceği deformasyonlara karşı hassas bir yapıdadır (Türk, 2015).

Bu bilgiler 1şı̆̆ında, analizler sonucunda Sentinel-1 veri seti için, radar bakış yönündeki (Line of Sight, LOS) ortalama deformasyonun hız haritaları üretilmiştir. Ordu-Giresun Havalimanı için Sentinel-1 verilerinin ortalama LOS hızları Şekil 5'te gösterilmektedir. Alçalan yörünge için elde edilen LOS hız sonuçlarında, havalimanının kuzey bölümlerinde genel olarak kırmızı (yani negatif hız) renklerde, güneyinde ise hem kırmızı hem de mavi (yani pozitif hız) renklerinde hızlar gözlemlenmiştir. Alanın güney bölümü her iki rengi içermesine rağmen mavi renkteki hızların daha fazla olduğu dikkat çekmektedir. Elde edilen sonuçlar LOS yönünde ve bağıl hareketlerdir. Bu durum kırmızı renk ve tonlarına sahip noktaların zaman içindeki geçişlerde uydudan uzaklaşmış olduğunu, mavi renk ve tonlarına sahip noktaların ise zaman içindeki geçişlerde uyduya yakınlaşmış olduğunu gösterir. Şekil 5'te görüldüğü gibi arazideki yıllık deformasyon -14 ile 9 mm arasında değişmektedir. Bu tip dolgu alanlarında meydana gelen yüzey deformasyonlarına sebep olarak taşıma kapasitelerindeki zayıflığı söylenebilir. Bu arazi parçalarının üzerine inşa edilen yapılara karşı hassas ve zaman içinde jeolojik 
olarak yer değiştirme özeliklerine sahip olmaları da diğer bir etken olarak gösterilebilir (Bianchini Ciampoli vd., 2020; Gao vd., 2019; Jiang vd., 2016; Marshall vd., 2018). Şekil 5'te bulunan sarı daire içinden elde edilen zaman serisi Şekil 6'da verilmiştir.

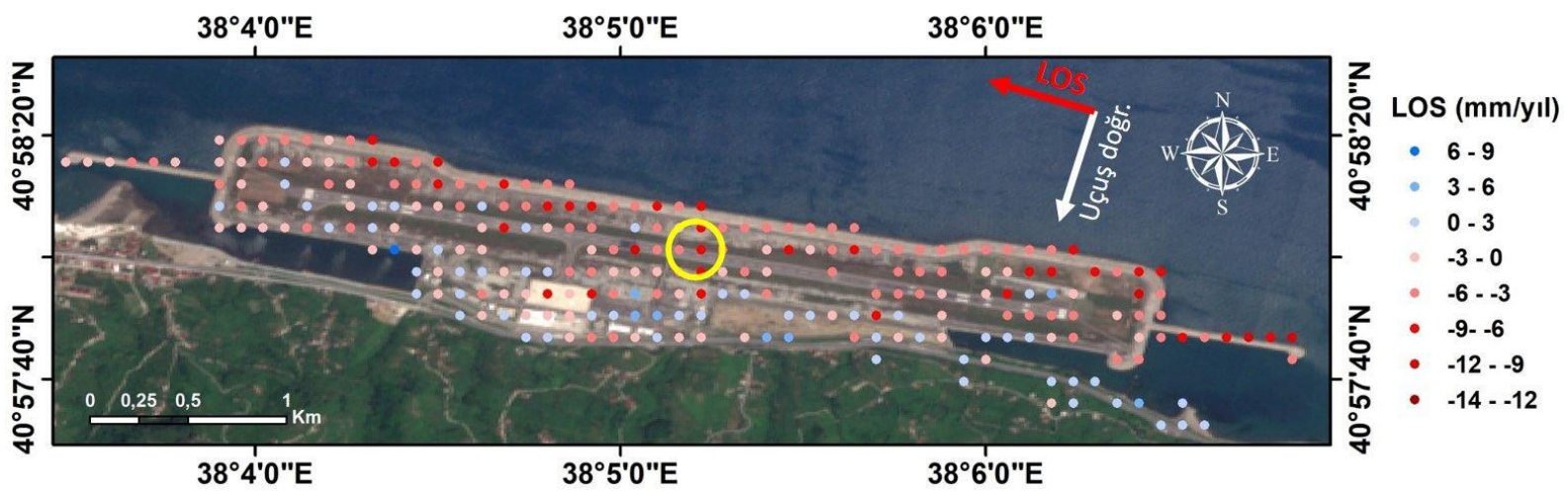

Şekil 5: Sentinel-1 LOS hız haritası

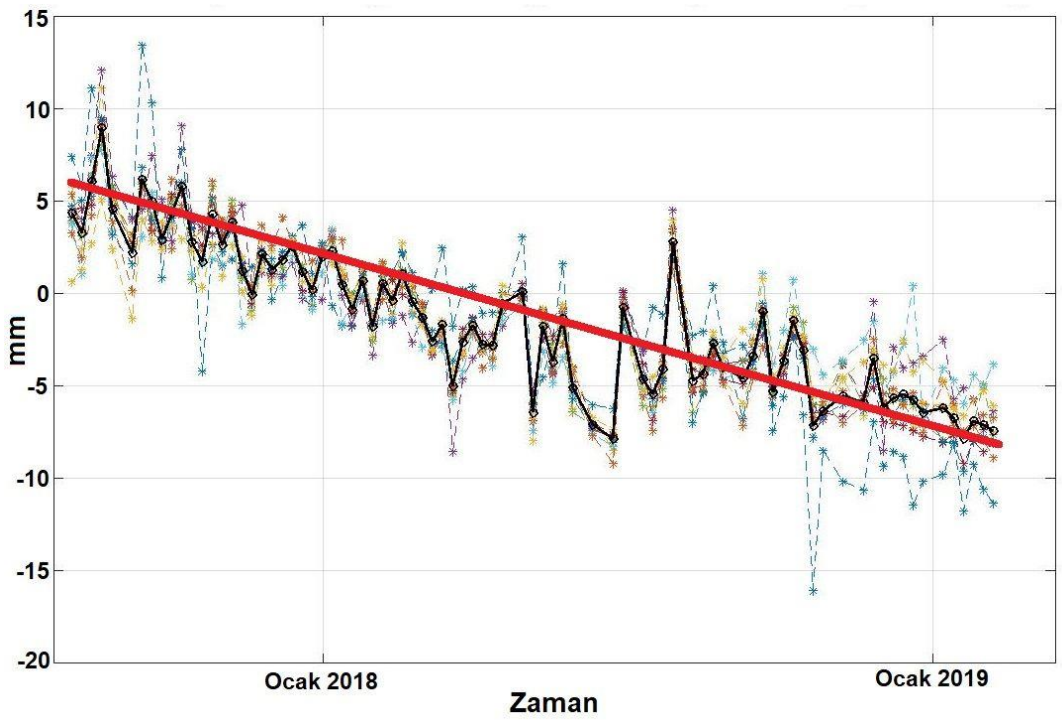

Şekil 6: Zaman serisi örneği

\section{Sonuçlar}

Bu çalışmada, Ordu ve Giresun illerinin sınırına yakın kıyılarda deniz üzerine dolgu yapılarak inşa edilmiş olan Ordu-Giresun Havalimanı'nda meydana gelen yüzey hareketleri incelenmiştir. Bu amaçla Ağustos 2017-Şubat 2019 yılları arasında uzun vadeli ve yavaş gelişen hareketler araştırılmıştır. Bu bağlamda, bu tür yapıların yer değiştirme hareketlerini izleme ve görüntüleme amacı için en uygun teknikler arasında yer alan PSI teknolojisi kullanılarak zaman serileri elde edilmiştir. $\mathrm{Bu}$ zaman serileri Sentinel-1A/B uydusuna ait SLC formatında ve alçalan yörüngede temin edilmiş 84 adet görüntü ile elde edilen veri kümesi ile gerçekleştirilmiştir. Elde edilen sonuçlar LOS yönünde belirlenmiştir. Buna göre Ordu-Giresun Havalimanı'nda meydana gelen yüzey değişimi -14 ila $9 \mathrm{~mm}$ arasında belirlenmiştir. T.C. Ulaştırma, Denizcilik ve Haberleşme Bakanlığ1 (2012) raporuna göre alanın sağlam bir zemin özelliği göstereceği ve zamana bağlı bir oturma probleminin olmayacağı belirtilmiştir. Yapılan çalışmaya göre beklenti olmamasına rağmen InSAR ile hareket gözlenmektedir. Hareket genel olarak havalimanı kuzey bölgelerinde çökmeler şeklinde belirlenirken, güney bölümlerinde ise yükselmenin daha baskın olduğu fakat yer yer çökmeler şeklinde meydana geldiği belirlenmiştir. Yakın olduğu nüfus 
bölgelerine etkisi ve işletme güvenliği düşünüldüğünde bu yapının deformasyonunun izlenmesi ve görüntülenmesi oldukça önemlidir. Önümüzdeki çalışmalarda havalimanında meydana gelen bu yüzey hareketlerinin daha geniş bir zaman aralığı ve birbirinden farklı iki yörünge görüntüleri ile incelenmesi planlanmaktadır.

\section{Teşekkür}

Yazar, çalışmada kullanılan InSAR verileri için Avrupa Uzay Ajansı'na (ESA) teşekkür eder.

\section{Çıkar Çatışması Beyanı}

Yazar, bu çalışmada bilinen ilgili herhangi bir finansal veya finansal olmayan çıkar çatışması olmadığını beyan eder.

\section{Kaynaklar}

Abdikan, S., Arıkan, M., Şanlı, F. B., \& Çakır, Z. (2014). Monitoring of coal mining subsidence in peri-urban area of Zonguldak city (NW Turkey) with persistent scatterer interferometry using ALOS-PALSAR. Environmental Earth Sciences, 71(9), 4081-4089.

Bianchini Ciampoli, L., Gagliardi, V., Ferrante, C., Calvi, A., D’Amico, F., \& Tosti, F. (2020). Displacement monitoring in airport runways by persistent scatterers SAR interferometry. Remote Sensing, 12(21), 3564.

Capaldo, P., Crespi, M., Fratarcangeli, F., Nascetti, A., \& Pieralice, F. (2011). High-resolution SAR radargrammetry: A first application with COSMO-SkyMed spotlight imagery. IEEE Geoscience and Remote Sensing Letters, 8(6), 1100-1104.

Chen, B., Gong, H., Li, X., Lei, K., Gao, M., Zhou, C., \& Ke, Y. (2015). Spatial-temporal evolution patterns of land subsidence with different situation of space utilization. Natural Hazards, 77(3), 1765-1783.

Chen, M., Tomás, R., Li, Z., Motagh, M., Li, T., Hu, L., Gong, H., Li, X., Yu, J., \& Gong, X. (2016). Imaging land subsidence induced by groundwater extraction in Beijing (China) using satellite radar interferometry. Remote Sensing, 8(6), 468.

Dai, K., Shi, X., Gou, J., Hu, L., Chen, M., Zhao, L., Dong, X., \& Li, Z. (2020). Diagnosing Subsidence Geohazard at Beijing Capital International Airport, from High-Resolution SAR Interferometry. Sustainability, 12(6), 2269.

Ding, X. L., Liu, G. X., Li, Z. W., Li, Z. L., \& Chen, Y. Q. (2004). Ground subsidence monitoring in Hong Kong with satellite SAR interferometry. Photogrammetric Engineering \& Remote Sensing, 70(10), 1151-1156.

Douglas, I., \& Lawson, N. (2003). Airport construction: materials use and geomorphic change. Journal of Air Transport Management, 9(3), $177-185$.

Ferretti, A., Prati, C., \& Rocca, F. (2000). Nonlinear subsidence rate estimation using permanent scatterers in differential SAR interferometry. IEEE Transactions on geoscience and remote sensing, 38(5), 2202-2212.

Ferretti, A., Prati, C., \& Rocca, F. (2001). Permanent scatterers in SAR interferometry. IEEE Transactions on geoscience and remote sensing, 39(1), 8-20.

Gao, M., Gong, H., Li, X., Chen, B., Zhou, C., Shi, M., Guo, L., Chen, Z., Ni, Z., \& Duan, G. (2019). Land subsidence and ground fissures in Beijing capital international airport (bcia): Evidence from quasi-ps insar analysis. Remote Sensing, 11(12), 1466.

Garthwaite, M. C. (2017). On the design of radar corner reflectors for deformation monitoring in multi-frequency InSAR. Remote Sensing, 9(7), 648 .

Hanssen, R. F. (2001). Radar Interferometry: Data Interpretation and Error Analysis. Springer: Berlin, Germany.

Higgins, S. A., Overeem, I., Steckler, M. S., Syvitski, J. P., Seeber, L., \& Akhter, S. H. (2014). InSAR measurements of compaction and subsidence in the Ganges-Brahmaputra Delta, Bangladesh. Journal of Geophysical Research: Earth Surface, 119(8), $1768-1781$.

Hoeksema, R. J. (2007). Three stages in the history of land reclamation in the Netherlands. Irrigation and Drainage: The journal of the International Commission on Irrigation and Drainage, 56(S1), S113-S126.

Hooper, A., Zebker, H., Segall, P., \& Kampes, B. (2004). A new method for measuring deformation on volcanoes and other natural terrains using InSAR persistent scatterers. Geophysical research letters, 31(23). 
Hooper, A., Spaans, K., Bekaert, D., Cuenca, M. C., Arıkan, M., \& Oyen, A. (2010). StaMPS/MTI manual. Delft Institute of Earth Observation and Space Systems Delft University of Technology, Kluyverweg, 1, 2629.

Hu, J., Li, Z. W., Ding, X. L., Zhu, J. J., Zhang, L., \& Sun, Q. (2012). 3D coseismic displacement of 2010 Darfield, New Zealand earthquake estimated from multi-aperture InSAR and D-InSAR measurements. Journal of Geodesy, 86(11), 1029-1041.

Jiang, L., \& Lin, H. (2010). Integrated analysis of SAR interferometric and geological data for investigating long-term reclamation settlement of Chek Lap Kok Airport, Hong Kong. Engineering Geology, 110(3-4), 77-92.

Jiang, Y., Liao, M., Wang, H., Zhang, L., \& Balz, T. (2016). Deformation monitoring and analysis of the geological environment of Pudong international airport with persistent scatterer SAR interferometry. Remote Sensing, 8(12), 1021.

Kampes, B. M. (2006). The Permanent Scatterer Technique. Radar Interferometry: Persistent Scatterer Technique. Springer: Dordrecht, The Netherlands.

Liu, G., Ding, X., Chen, Y., Li, Z., \& Li, Z. (2001). Ground settlement of Chek Lap Kok Airport, Hong Kong, detected by satellite synthetic aperture radar interferometry. Chinese Science Bulletin, 46(21), 1778-1782.

Marshall, C., Large, D. J., Athab, A., Evers, S. L., Sowter, A., Marsh, S., \& Sjögersten, S. (2018). Monitoring tropical peat related settlement using isbas insar, kuala lumpur international airport (klia). Engineering Geology, 244, 57-65.

Pickles, A. R., \& Tosen, R. (1998). Settlement of Reclaimed Land for the New Hong Kong International Airport. Proceedings of the Institution of Civil Engineers-Geotechnical Engineering, 131(4), 191-209.

Plant, G. W., Covil, C. S., \& Hughes, R. A. (1998). Site Preparation for the New Hong Kong International Airport-The Design,Construction and Performance of the Airport Platform. Thomas Telford: London, UK.

Pritchard, M. E., \& Simons, M. (2004). An InSAR-based survey of volcanic deformation in the central Andes. Geochemistry, Geophysics, Geosystems, 5(2).

Puzrin, A. M., Alonso, E. E., \& Pinyol, N. M. (2010). Unexpected excessive settlements: Kansai international airport, Japan. In Geomechanics of failures. Springer: Dordrecht, The Netherlands.

Sefercik, U. G., Yastıkl1, N., \& Atalay, C. (2017). Terrain estimation performance of advanced SAR satellites: Cosmo-SkyMed and TerraSAR-X. 2017 8th International Conference on Recent Advances in Space Technologies (RAST).

Simons, M., Fialko, Y., \& Rivera, L. (2002). Coseismic deformation from the 1999 M w 7.1 Hector Mine, California, earthquake as inferred from InSAR and GPS observations. Bulletin of the Seismological Society of America, 92(4), 1390-1402.

T.C. Ulaştırma, Denizcilik ve Haberleşme Bakanlığı (2012). Ordu-Giresun Havaalanı Kesim-1 (Tahkimat Km: 0+000-1+500) Deniz Dolguları Revize Geoteknik Proje Raporu. Altyapı Yatırımları Genel Müdürlüğü, Ankara.

Terzaghi, K., Peck, R. B., \& Mesri, G. (1996). Soil Mechanics in Engineering Practice. John Wiley and Sons: Hoboken, NJ, USA.

Türk, H. (2015). Ordu Giresun Havalimanı (Mekan Seçimi ve Muhtemel Etkileri) (Yüksek Lisans Tezi). Giresun Üniversitesi, Sosyal Bilimler Enstitüsü, Giresun, Türkiye.

Xu, B., Feng, G., Li, Z., Wang, Q., Wang, C., \& Xie, R. (2016). Coastal subsidence monitoring associated with land reclamation using the point target based SBAS-InSAR method: A case study of Shenzhen, China. Remote Sensing, 8(8), 652.

Yang, M., Yang, T., Zhang, L., Lin, J., Qin, X., \& Liao, M. (2018). Spatio-temporal characterization of a reclamation settlement in the Shanghai coastal area with time series analyses of X-, C-, and L-band SAR datasets. Remote Sensing, 10(2), 329.

Ye, X., Kaufmann, H., \& Guo, X. F. (2004). Landslide monitoring in the Three Gorges area using D-InSAR and corner reflectors. Photogrammetric Engineering \& Remote Sensing, 70(10), 1167-1172.

Zhao, Q., Lin, H., Gao, W., Zebker, H. A., Chen, A., \& Yeung, K. (2011). InSAR detection of residual settlement of an ocean reclamation engineering project: a case study of Hong Kong International Airport. Journal of oceanography, 67(4), 415-426.

Zhuo, G., Dai, K., Huang, H., Li, S., Shi, X., Feng, Y., Li, T., Dong, X., \& Deng, J. (2020). Evaluating potential ground subsidence geohazard of Xiamen Xiang'an new airport on reclaimed land by SAR interferometry. Sustainability, 12(17), 6991.

URL-1: https://tr.wikipedia.org/wiki/Ordu-Giresun_Havaliman\%C4\%B1 (Erişim Tarihi: 6 Aralık 2020).

URL-2: Sea Level Rise in the SF Bay Area Just Got a Lot More Dire. https://www.wired.com/story/sea-level-rise-in-the-sf-bayarea/?verso=true (Erişim Tarihi: 28 Ocak 2021).

Jeo. Jeolnf. Derg., 2021, 8(2):161-169 